\title{
Comparative study on the efficacy of non-steroidal, steroid and non-use of anti-inflammatory in the treatment of acute epidemic conjunctivitis ${ }^{1}$
}

Luiz Alfredo Santiago' (D), Jussara Matyelle Rodrigues da Silva" (D), Orleâncio Gomes Ripardo de Azevedo"II (D) , Paulo Roberto Leitão de Vasconcelos ${ }^{\text {IV }}$

' Master in Surgery, and Physician, Hospital de Olhos Leiria de Andrade, Fortaleza-CE, Brazil. Acquisition of data, technical procedures, manuscript writing.

"Fellow Master degree, Pharmacology Department, Universidade Federal do Ceará (UFC), Fortaleza-CE, Brazil. Statistical analysis, analysis and interpretation of data, technical procedures.

II'Pos Doc, Postgraduate Program, Department of Surgery, UFC, Fortaleza-CE, Brazil. Manuscript preparation and writing, critical revision

IV PhD, Full Professor, Coordinator, Postgraduate Program in Surgery, Department of Surgery, UFC, Fortaleza-CE, Brazil. Intellectual and scientific content of the study, critical revision, final approval.

\begin{abstract}
Purpose: To evaluate the effects of prednisolone against sodium diclofenac both with ciprofloxacin compared to artificial tears on the symptoms and signs of acute viral conjunctivitis.

Methods: Study included 37 patients diagnosed with acute conjunctivitis and distributed by three groups: A (1\% prednisolone acetate + ciprofloxacin (0.3\%); B (Sodium diclofenac $(0.1 \%)+$ ciprofloxacin $(0.3 \%)$ and $C$ (artificial tears + ciprofloxacin (0.3\%). Patients received medication $6 / 6$ hours daily. Signs and symptoms (e.g. lacrimation, burning, photophobia, etc.) were scored at baseline and on the first, third, fifth and seventh days and in the end of treatment using a standardized questionnaire and slit lamp anterior segment examination.

Results: All three groups demonstrated an improvement in the signs and symptoms of conjunctivitis in their follow-up visits. There was no significant difference in symptom and sign scores between Group $A$ and $B$ and $B$ and $C$ in the study visits $(p>0.05)$. However, the comparison between groups $A$ and $C$ showed a clinical trend $(p=0.05)$ on third evaluation suggesting better clinical action using the corticosteroids.
\end{abstract}

Conclusion: The prednisolone acetate was not superior to the use of sodium diclofenac or artificial tears in relieving the signs and symptoms of viral conjunctivitis.

Key words: Conjunctivitis. Adrenal Cortex Hormones. Cytokines. 


\section{- Introduction}

Approximately $70 \%$ of patients with acute conjunctivitis present to their primary care provider or an urgent care center rather than to an ophthalmologist ${ }^{1}$. Conjunctivitis is a common complaint in primary care, affecting all ages and socioeconomic classes affecting 6 million people annually in the United States ${ }^{2,3}$.

Infectious conjunctivitis can have several etiologic factors, such as bacterial, viral, chlamydial, fungal, and parasitic. In addition, non-infectious conjunctivitis includes allergens, toxicities, and irritants ${ }^{4}$.

Common viral agents include adenovirus, herpes simplex, herpes zoster, and enterovirus. Allergic conjunctivitis encompasses seasonal allergic conjunctivitis, perennial allergic conjunctivitis, vernal keratoconjunctivitis (VKC), atopic keratoconjunctivitis $(\mathrm{AKC})$, and giant papillary conjunctivitis ${ }^{4}$.

Conjunctivitis can be further divided into acute or chronic types. Acute conjunctivitis is characterized by onset within 3 to 4 weeks of the presentation and chronic is defined as more than 4 weeks in duration ${ }^{5}$.

Acute conjunctivitis is usually a self-limiting condition; however, it is important to rule out other sight-threatening red eye diseases. Viral conjunctivitis is an extremely common cause of conjunctivitis, with estimates as high as $80 \%$ of all causes of acute conjunctivitis ${ }^{6}$.

As many as $90 \%$ of these cases of viral conjunctivitis are thought to be caused by human adenovirus, which is known to cause 2 distinct syndromes: epidemic keratoconjunctivitis and pharyngoconjunctival fever ${ }^{7}$.

Viral conjunctivitis is highly contagious ${ }^{1,5}$. The virus spreads through direct contact via contaminated fingers, medical instruments, swimming pool water, or personal items; in one study, $46 \%$ of infected people had positive cultures grown from swabs of their hands $^{8}$. Because of the high rates of transmission, hand washing, strict instrument disinfection, and isolation of the infected patients from the rest of the clinic has been advocated ${ }^{9}$. Incubation and communicability are estimated to be 5 to 12 days and 10 to 14 days, respectively ${ }^{10}$.

Although no effective treatment exists, artificial tears, topical antihistamines, or cold compresses may be useful in alleviating some of the symptoms ${ }^{11}$. Available antiviral medications are not useful ${ }^{10}$ and topical antibiotics are not indicated ${ }^{11}$.

In hospitalized patients, a randomized study compared topical ketorolac $0.5 \%$ and indomethacin $0.1 \%$ to artificial tears ${ }^{12}$. Ketorolac and indomethacin were more effective in decreasing conjunctival hyperemia, but burning, foreign--body sensations, and photophobia were unaffected. In a different randomized study of 117 patients, topical ketorolac $0.5 \%$ used four times daily was no better than artificial tears in relieving signs (conjunctival injection, chemosis, mucus, and lid edema) and symptoms (itching, foreign body sensation, tearing, redness, lid swelling, and overall discomfort) of viral conjunctivitis ${ }^{13}$.

In a rabbit ocular model to evaluate antiviral activity, neither $0.5 \%$ ketorolac nor $0.1 \%$ diclofenac demonstrated inhibitory activity on viral replication or the formation of subepithelial immune infiltrates. In contrast, 1\% prednisolone acetate prolonged viral shedding. Thus, the objective of this study was to evaluate the effects of the administration of prednisolone against sodium diclofenac both associated with ciprofloxacin compared to artificial tears on the symptoms and signs of acute viral conjunctivitis.

\section{- Methods}

The research project, with the experimental protocol and the consent term, was submitted to the Research Ethics Committee, Universidade Federal do Ceará, accredited by CONEP - Conselho Nacional de Saúde / MS and approved - Protocol No. 118/11 according with the Helsinki Declaration of 1975 as revised in 2008. All the protocols were adequate to the resolution 466/12 of Health Ministry.

In the current study, 37 patients, 20 women and 17 men, were divided into 3 groups; $A(n=16), B(n=5)$ and $C(n=16)$, constituting people of both genders with ages between 18 and 70 years. Patients were invited based on clinical history and slit lamp examination, where they were examined prior to initiation of treatment and at the end of the study, being followed up every 3 days.

To guarantee the homogeneity of the characteristics between the study groups, a block randomization was adopted ${ }^{11}$. Fixed-size blocks of nine envelopes were used, of which 3 were with medication group $A$, 3 with group $B$ and 3 with group $C$. At the beginning of each block a lottery was made to indicate which medication to use.

The medication was administered for 15 days of treatment with corticoid eye drops (1\% prednisolone acetate) and sodium diclofenac sodium eye drops. Antibiotic eye drops (ciprofloxacin $0.3 \%$ ) were also used, because it is common for epidemic conjunctivitis of viral cause, to complicate with a bacterial infection ${ }^{(12)}$. For the relief of symptoms in group $\mathrm{C}$, artificial tears were used. 


\section{Symptoms assessment}

For overall assessment of relief, patients answered the following question: Do you consider the relief of conjunctivitis symptoms satisfactory during the last 15 days? The answer was yes or no.

\section{Inflammatory markers panel}

Dosage of inflammatory mediators: through conjunctival smears and conjunctival secretion, with an absorbent ophthalmic sponge, performed only in the most symptomatic eye ${ }^{13,14}$, at the last evaluation. The kit - cat HCYTOMAG - 60K - 07 was used to measure the following cytokines: IFNg, IL - 1a, IL - 6, IL - 8, IL - 10, IL - 13, TNF-a. Kit 46-702 MAG / MILLIPLEX MAP ${ }^{\circledR}$, for NFkB. Kit cat \# MBS723617 for iNOS.

After collection the sponge was placed in the $1.5 \mathrm{ml}$ Eppendorf ${ }^{\circledR}$ tube, where they were centrifuged 5 minutes at $8000 \mathrm{rpm}$. With forceps the sponge was disposed. For analysis it was ideal to obtain at least
40 microliters. Samples were stored in a drum with liquid nitrogen.

\section{Statistics}

The Friedman test was applied in each group and in total. When the independent variable had three or more groups ANOVA was used with Bonferri posttest for multiple comparisons. The $\mathrm{P}<0.05$ was considered to characterize the statistical difference between the groups.

\section{- Results}

This report analyzed 37 patients, $54.1 \%$ (20/37) female and $45.9 \%$ (17/37) male. The study divided the subjects in three groups A, B and C, all the patients did not demonstrate any significant difference, in the beginning of the experiment, between the median of symptoms $36.8( \pm 1.9), 29.8( \pm 2.8)$, and $32.1( \pm 2.2)$ respectively (Table 1 ).

Table 1 - Comparison of means of symptoms by group and period, with $95 \% \mathrm{Cl}$.

\begin{tabular}{lcccc}
\hline Evaluations & A & B & C & Total \\
\hline Pre-study & $36.8( \pm 1.9)$ & $29.8( \pm 2.8)$ & $32.1( \pm 2.2)$ & $33.8( \pm 1.4)$ \\
1st evaluation & $26.2( \pm 1.8)$ & $26.3( \pm 2.0)$ & $25.1( \pm 1.9)$ & $25.7( \pm 1.1)$ \\
2nd evaluation & $11.9( \pm 1.8)$ & $15.7( \pm 4.0)$ & $17.9( \pm 2.4)$ & $15.0( \pm 1.4)$ \\
3rd evaluation & $5.8( \pm 1.1)$ & $14.1( \pm 3.8)$ & $13.4( \pm 1.9)$ & $10.2( \pm 1.2)$ \\
4th evaluation & $1.1( \pm 0.5)$ & $10.2( \pm 3.6)$ & $1.1( \pm 0.4)$ & $4.1( \pm 0.9)$ \\
Closing & $0.0( \pm 0.0)$ & $6.7( \pm 2.4)$ & $<0.001$ & $1.4( \pm 0.5)$ \\
P-value* & $<0.001$ & $<0.001$ & $<0.001$ \\
\hline
\end{tabular}

The table shows the means of symptoms along the points of evaluation during the treatment demonstrating a decreasing of the symptoms despite of the protocol of treatment.

The values correspond to the following nomenclature: mean $( \pm 95 \% \mathrm{Cl})$.

*Friedman test.

Source: Data generated by the author.

All patients demonstrated a decrease in the symptom severity during the period of evaluation. However, group A demonstrated an important decrease of $54.5 \%$ from the $1^{\text {st }}$ to $2^{\text {nd }}$ evaluation, while groups B and C showed a decrease of $40.3 \%$ and $28.9 \%$ respectively. Group A $(n=16)$ received prednisolone (1\%) plus ciprofloxacin (0.3\%) demonstrated a trend in improvement of the symptoms when compared to group $C(n=16)$ that received artificial tears plus ciprofloxacin $(0.3 \%)$ in third evaluation $(p=0.055)$; however, no statistical difference was observed between $A$ and $B$ or between $B$ and $C$ groups in the $1^{\text {st }}, 2^{\text {nd }} 3^{\text {rd }}, 4^{\text {th }}$ evaluation and in the last assessment respectively (Table 2 ). 
Table 2 - Comparison of means of symptoms between groups, by period, with $95 \% \mathrm{Cl}$.

\begin{tabular}{|c|c|c|c|c|c|c|}
\hline \multirow{2}{*}{$\begin{array}{l}\text { Period of } \\
\text { evaluation }\end{array}$} & \multirow{2}{*}{$\mathbf{A}$} & \multirow{2}{*}{ B } & \multirow{2}{*}{ C } & \multicolumn{3}{|c|}{ P-value } \\
\hline & & & & A -- B & $A--C$ & B -- C \\
\hline Pre-study & $18.8( \pm 1.9)$ & $15.2( \pm 2.8)$ & $16.4( \pm 2.2)$ & 0.981 & $>0.999$ & $>0.999$ \\
\hline 1st evaluation & $13.4( \pm 1.8)$ & $13.4( \pm 2.0)$ & $12.8( \pm 1.9)$ & $>0.999$ & $>0.999$ & $>0.999$ \\
\hline 2nd evaluation & $6.1( \pm 1.8)$ & $8.0( \pm 4.0)$ & $9.1( \pm 2.4)$ & $>0.999$ & 0.996 & $>0.999$ \\
\hline 3rd evaluation & $2.9( \pm 1.1)$ & $7.2( \pm 3.8)$ & $6.8( \pm 1.9)$ & 0.944 & 0.055 & $>0.999$ \\
\hline 4th evaluation & $0.6( \pm 0.5)$ & $5.2( \pm 3.6)$ & $2.7( \pm 1.3)$ & 0.538 & 0.307 & $>0.999$ \\
\hline Closing & $0.0( \pm 0.00)$ & $3.40( \pm 2.45)$ & $0.6( \pm 0.4)$ & 0.301 & 0.757 & 0.857 \\
\hline
\end{tabular}

The values correspond to the following nomenclature: mean $( \pm 95 \% \mathrm{Cl})$.

*Friedman test.

Source: Data generated by the author.

Collected tears were assessed for inflammation using an inflammatory marker panel as described in methods. There were no statistical differences observed between the groups studied, IFNg ( $p=0.447)$, IL-10 (0.505), IL-13 (0.641), IL-1a (0.859); IL-8 (0.177); TNF-a (0.735) (Table 3).

Table 3 - Levels of inflammatory markers in groups A, B and C.

\begin{tabular}{|c|c|c|c|c|c|c|c|c|c|}
\hline \multirow{2}{*}{ Mediator } & \multirow{2}{*}{ Median } & \multirow{2}{*}{ IC $95 \%$} & \multicolumn{2}{|r|}{ Group A } & \multicolumn{2}{|r|}{ Group B } & \multicolumn{2}{|r|}{ Group C } & \multirow{2}{*}{ P-value } \\
\hline & & & Median & IC $95 \%$ & Median & IC $95 \%$ & Median & IC $95 \%$ & \\
\hline IFNy & 4.58 & $(1.91-11.05)$ & 2.80 & $(1.10-11.05)$ & 28.37 & $(1.39-467.00)$ & 8.01 & $(2.94-19.15)$ & 0.447 \\
\hline IL-10 & 8.67 & $(2.64-27.06)$ & 5.31 & $(1.45-23.97)$ & 206.43 & $(1.33-775.00)$ & 23.29 & $(5.54-53.34)$ & 0.505 \\
\hline IL-13 & 17.07 & $(11.88-26.67)$ & 18.42 & $(2.79-30.22)$ & 12.38 & $(12.38-19.81)$ & 25.50 & $(8.54-43.45)$ & 0.641 \\
\hline IL-1a & 11.70 & $(8.55-21.59)$ & 11.79 & $(4.24-43.81)$ & 57.28 & $(0.45-133.00)$ & 11.70 & $(8.11-22.58)$ & 0.859 \\
\hline IL-6 & 20.03 & $(13.52-35.62)$ & 9.46 & $(5.97-22.10)$ & 74.81 & $(6.24-618.00)$ & 26.22 & $(17.66-70.19)$ & 0.184 \\
\hline IL-8 & 441.00 & $(254.00-681.00)$ & 445.00 & $(215.00-681.00)$ & 1366.50 & $(254.00-2927.00)$ & 254.00 & $(94.61-803.00)$ & 0.177 \\
\hline TNFa & 10.98 & $(5.63-26.36)$ & 12.79 & $(2.71-37.81)$ & 69.28 & $(0.68-928.00)$ & 8.81 & $(5.63-28.12)$ & 0.735 \\
\hline iNOS & 0.00 & $(0.00-0.00)$ & 0.00 & $(0.00-0.00)$ & 0.00 & $(0.00-0.00)$ & 0.00 & $(0.00-0.00)$ & - \\
\hline
\end{tabular}

The values correspond to the following nomenclature: mean $( \pm 95 \% \mathrm{Cl})$.

*Friedman test.

Source: Data generated by the author.

\section{- Discussion}

Report from the Wills Eye Hospital at Florida demonstrated prevalence of $62 \%$ of adenoviral conjunctivitis amongst all subjects presenting clinical diagnosis of infectious conjunctivitis ${ }^{14,15}$. Viruses are associated with up to $80 \%$ of all prevalence of acute conjunctivitis ${ }^{16-20}$

65 to $90 \%$ of cases of viral conjunctivitis are caused by adenoviruses, and it produces two common clinical symptoms related to viral conjunctivitis: pharyngoconjunctival fever (high fever, pharyngitis and bilateral conjunctivitis) and keratoconjunctivitis (lymphadenopathy). In another report from Southeastern Brazil, in Sao Paulo, the authors found a prevalence of $59.0 \%$ with acute conjunctivitis associated with adenovirus diagnosed by $\mathrm{PCR}^{21}$. In addition, in Northeastern Brazil, in Fortaleza, a study assessing 24 patients demonstrated that $12(50 \%)$ tested positively for viral infection ${ }^{22}$.

This report did not show any significant differences between treatment with NSAID and steroids in signs 
of conjunctivitis. Keratoconjunctivitis is frequently associated with outbreaks, and is also commonly related to the adenovirus serotypes ${ }^{25,26}$.

The treatment of keratoconjunctivitis targets reduction in redness, itching, tearing, blurry vision, chemosis and eyelid oedema ${ }^{14,26}$. To this end, there are a variety of topical preparations, each working on a different phase in the inflammatory process, in order to manage those signs ${ }^{28}$. The treatment of conjunctivitis includes steroids ${ }^{23}$ and NSAID $^{24}$. This report aimed to demonstrate that the use of anti-inflammatory NSAIDs or corticosteroid could improve the inflammatory status in eye mucosa during conjunctivitis. However, the study could not demonstrate a statistical difference between the treatments. Nevertheless, the report found a clinical trend in the third evaluation between the groups $A$ compared to group $B$.

In another similar report evaluating sixty patients clinically diagnosed with a different kind of conjunctivitis [Seasonal Allergic Conjunctivitis (SAC)], the patients were treated with diclofenac $(0.1 \%)$ and ketorolac $(0.5 \%)$, and the authors demonstrated an improvement on the symptoms (e.g., burning/stinging, discharge / tearing, photophobia, foreign body sensation and swollen eye) in both treatments. In final analysis the therapeutic response did show an improvement on incomes in group treated with ketorolac $(0.5 \%)^{28}$. On the other hand, in a study from Recife, Brazil, the authors, evaluating fifty patients with symptoms of acute viral conjunctivitis, a group of twenty-four patients treated with ketorolac $(0.45 \%)$ plus carboximetilcelulose and the other group with twenty-six patients received artificial tears, demonstrated no statistical difference between the two types of treatment ${ }^{29}$.

Nevertheless Swany et $a .^{30}$, analyzing eight clinical studies with 712 patients involved with allergic conjunctivitis, demonstrated that use of NSAID produced significant relief of inflammatory conjunctival itching; however, for the other inflammatory signs (e.g. ocular burning/pain, eyelid swelling, photophobia and foreign sensation), the data were not significant, similar to the findings of this study.

Thus, based on this report there is limited evidence to support the use of topical NSAID in viral acute conjunctivitis. Further studies are needed to compare the efficacy of non-hormonal anti-inflammatory, hormonal (steroid) and non-use of anti-inflammatory in acute epidemic and endemic conjunctivitis, through dosage of inflammatory mediators, and clinical status using a higher number of patients.

In this report, no equivalent work was found, being considered the first research in this specific aim. Our observation suggests that in the current study, there was a clinical difference in the group treated with corticoid; however, it was not statistically significant.

\section{- Conclusion}

There was no statistical difference between the treatments tested, but in the clinical symptoms of the patients, we can report that there was a clinical trend of improvement for those who received corticosteroid.

\section{- Acknowledgement}

To Dr. David Bollick (University of Virginia) for his English considerations. We appreciate the time spent reading and correcting our article.

\section{- References}

1. Kaufman HE. Adenovirus advances: new diagnostic and therapeutic options. Curr Opin Ophthal. 2011;22(4):290-3. doi: 10.1097/ICU.0b013e3283477cb5.

2. Shields T, Sloane PD. A comparison of eye problems in primary care and ophthalmology practices. Fam Med. 1991;23(7):544-6.

3. Udeh BL, Schneider JE, Ohsfeldt RL. Cost effectiveness of a point-of-care test for adenoviral conjunctivitis. Am J Med Sci. 2008;336(3):254-64. doi: 10.1097/ MAJ.0b013e3181637417.

4. Watson S, Cabrera-Aguas M, Khoo P. Common eye infections. Aust Prescr. 2018;41(3):67-72. doi: 10.18773/ austprescr.2018.016.

5. Høvding G. Acute bacterial conjunctivitis. Acta Ophthalmol. 2008;86(1):5-17. doi: 10.1111/j.1600-0420.2007.01006.x.

6. Azari AA, Barney NP. Conjunctivitis: a systematic review of diagnosis and treatment. JAMA. 2013;310(16):1721-30. doi: 10.1001/jama.2013.280318.

7. González-López JJ, Morcillo-Laiz R, Muñoz-Negrete FJ. Adenoviral keratoconjunctivitis: an update. Arch Soc Esp Oftalmol (English Edition). 2013;88(3):108-15. doi: 10.1016/j.oftale.2012.07.002.

8. Azar MJ, Dhaliwal DK, Bower KS, Kowalski RP, Gordon YJ. Possible consequences of shaking hands with your patients with epidemic keratoconjunctivitis. Am J Ophthalmol. 1996;121(6):711-2. doi: 10.1016/S0002-9394(14)70640-3.

9. Warren D, Nelson KE, Farrar JA, Hurwitz E, Hierholzer J, Ford E, Anderson LJ. A large outbreak of epidemic keratoconjunctivitis: problems in controlling nosocomial spread. J Infect Dis. 1989;160(6):938-43. doi: 10.1093/ infdis/160.6.938.

10. Skevaki CL, Galani IE, Pararas MV, Giannopoulou KP, Tsakris A. Treatment of viral conjunctivitis with antiviral drugs. Drugs. 2011;71(3):331-47. doi: 10.2165/11585330000000000-00000.

11. Wood M. Conjunctivitis: diagnosis and management. Community Eye Health. 1999;12(30):19-20. 
12. Toker MI, Erdem H, Erdogan H, Arici MK, Topalkara A, Arslan OS, Pahsa A. The effects of topical ketorolac and indomethacin on measles conjunctivitis: randomized controlled trial. Am J Ophthalmol. 2006;141(5):902-5. doi: 10.1016/j.ajo.2005.12.004.

13. Shiuey Y, Ambati BK, Adamis AP, Viral Conjunctivitis Study Group. A randomized, double-masked trial of topical ketorolac versus artificial tears for treatment of viral conjunctivitis. Ophthalmology. 2000;107(8):1512-7. doi: 10.1016/S0161-6420(00)00177-9.

14. Sambursky RP, Fram N, Cohen EJ. The prevalence of adenoviral conjunctivitis at the Wills Eye Hospital Emergency Room. Optometry. 2007;78(5):236-9. doi: 10.1016/j.optm.2006.11.012.

15. Sambursky R, Tauber S, Schirra F, Kozich K, Davidson R, Cohen EJ. The RPS adeno detector for diagnosing adenoviral conjunctivitis. Ophthalmology. 2006;113(10):1758-64. doi: 10.1016/j.ophtha.2006.06.029.

16. Stenson S, Newman R, Fedukowicz H. Laboratory studies in acute conjunctivitis. Arc Ophthalmol. 1982;100(8):1275-7. doi: 10.1001/archopht.1982.01030040253009.

17. Rönnerstam R, Persson KE, Hansson HO, Renmarker K. Prevalence of chlamydial eye infection in patients attending an eye clinic, a VD clinic, and in healthy persons. $\mathrm{Br} \mathrm{J}$ Ophthalmol. 1985;69(5):385-8. doi: 10.1136/bjo.69.5.385.

18. Harding SP, Mallinson H, Smith JL, Clearkin LG. Adult follicular conjunctivitis and neonatal ophthalmia in a Liverpool eye hospital, 1980-1984. Eye. 1987;1(4):512. doi: 10.1038/eye.1987.77.

19. Uchio E, Takeuchi S, Itoh N, Matsuura N, Ohno S, Aoki K. Clinical and epidemiological features of acute follicular conjunctivitis with special reference to that caused by herpes simplex virus type 1 . Br J Ophthalmol. 2000;84(9):968-72. doi: 10.1136/bjo.84.9.968.

20. Woodland RM, Darougar S, Thaker U, Cornell L, Siddique M, Wania J, Shah M. Causes of conjunctivitis and keratoconjunctivitis in Karachi, Pakistan. Trans $\mathrm{R}$ Soc Trop Med Hyg. 1992;86(3):317-20. doi: 10.1016/00359203(92)90328-A.
21. Pinto RD, Lira RP, Arieta CE, Castro RS, Bonon SH. The prevalence of adenoviral conjunctivitis at the Clinical Hospital of the State University of Campinas, Brazil. Clinics. 2015;70(11):748-50. doi: 10.6061/clinics/2015(11)06.

22. Moura FE, Ribeiro DC, Gurgel N, da Silva Mendes AC, Tavares FN, Timóteo CN, da Silva EE. Acute hemorrhagic conjunctivitis outbreak in the city of Fortaleza, northeast Brazil. Br J Ophthalmol. 2006;90(9):1091-3. doi: 10.1136/bjo.2006.098822.

23. Wilkins MR, Khan S, Bunce $C$, Khawaja A, Siriwardena D, Larkin DF. A randomized placebo-controlled trial of topical steroid in presumed viral conjunctivitis. $\mathrm{Br} J$ Ophthalmol. 2011;95(9):1299-303. doi: 10.1136/bjo.2010.188623.

24. Schechter BA. Ketorolac tromethamine $0.4 \%$ as a treatment for allergic conjunctivitis. Expert Opin Drug Metab Toxicol. 2008;4(4):507-11. doi: 10.1517/17425255.4.4.507.

25. Jin XH, Ishiko H, Ha NT, Ohguchi T, Akanuma M, Aoki K, Ohno S. Molecular epidemiology of adenoviral conjunctivitis in Hanoi, Vietnam. Am J Ophthalmol. 2006;142(6):1064-6. doi: 10.1016/j.ajo.2006.07.041.

26. Butt AL, Chodosh J. Adenoviral keratoconjunctivitis in a tertiary care eye clinic. Cornea. 2006;25(2):199-202. doi: 10.1097/01.ico.0000170693.13326.fb.

27. Lenaerts L, De Clercq E, Naesens L. Clinical features and treatment of adenovirus infections. Rev Med Virol. 2008;18(6):357-74. doi: 10.1002/rmv.589.

28. Dehar N, Gupta A, Singh G. Comparative study of the ocular efficacy and safety of diclofenac sodium (0.1\%) ophthalmic solution with that of ketorolac tromethamine (0.5\%) ophthalmic solution in patients with acute seasonal allergic conjunctivitis. Int J Appl Basic Med Res. 2012;2(1):25. doi: 10.4103/2229-516X.9679.

29. Lyra AF, Bastos LC, Lima RC, Maranhão LD, Arantes TE. Artificial tears alone versus $0.45 \%$ ketorolac tromethamine with artificial tears for the treatment of acute viral conjunctivitis. Arq Bras Oftamlmol. 2014;77(2):99-102. doi: 10.5935/0004-2749.20140025.

30. Swamy BN, Chilov M, McClellan K, Petsoglou C. Topical nonsteroidal anti-inflammatory drugs in allergic conjunctivitis: meta-analysis of randomized trial data. Ophthalmic Epidemiol. 2007;14(5):311-9. doi: 10.1080/09286580701299411.

\section{Correspondence:}

Orleâncio Gomes Ripardo de Azevedo

Rua Prof. Costa Mendes, 1608/3 andar, Bloco Didático

60430-140 Fortaleza - CE Brasil

Tels. (55 85)3366-8061 / 3366-8062

orleancio@gmail.com

Received: Aug 05, 2019

Review: Oct 08, 2019

Accepted: Nov 03, 2019
Conflict of interest: none

Financial source: none
${ }^{1}$ Research performed at Hospital de Olhos Leiria de Andrade, Fortaleza-CE, Brazil. 